\title{
SPACES THAT STIMULATE INNOVATION AND CREATIVITY AND PROVIDE A SENSE OF COMMUNITY AND PLACE - THREE CASE STUDIES FROM ZAGREB
}

DOI: 10.18485/arh_pt.2020.7.ch6

\author{
_ Bojan Baletić \\ Ph.D, Faculty of Architecture, University of Zagreb, \\ Kačićeva 26, 10000 Zagreb, bbaletic@arhitekt.hr

\section{_ Kristina Careva \\ Ph.D, Faculty of Architecture, University of Zagreb, Kačićeva 26, 10000 Zagreb, kcareva@arhitekt.hr} \\ - Morana Pap \\ Ph.D, Faculty of Architecture, University of Zagreb, \\ Kačićeva 26, 10000 Zagreb, mpap@arhitekt.hr
}

\begin{abstract}
The development of information technology and the global economy are causing the emergence of new forms of work and entrepreneurial collaborations. These changes are at the intersection of educational and business activities as well as creative and technological domains. This new design thinking culture requires a stimulating environment. For the last ten years, we have been researching new spatial configurations that provide support for creative and innovative processes. These facilities, with creative and social dynamic they provide, were put into the context of new campus planning, sustainable lifestyle promotion and urban regeneration founded on nature-based solutions. This paper discusses the spatial development of architectural spaces which can house a mix of activities (creation, innovation, enterprise) and offers an elaboration of their organizational and functional characteristics. Moreover, it puts their characteristics into the context of brownfield reuse for the establishment of a new urban identity and the quality of place. This innovative approach for new facilities has been validated by academic community and a local community in Zagreb.
\end{abstract}

KEYWORDS _ Innovative methods, design thinking, brownfield reuse, community-driven hub

\section{INTRODUCTION}

The present pandemic has put into sharp focus the ways in which our society is changing, such as: our global dependence, the possibilities of working online, the importance of the Internet technologies, but also a pressing need for real social interaction. The post-industrial transition has made profound changes to cities and the way we work. There is a growing presence of small and medium-sized enterprises which develop ideas and services as well as creative content. Creative and cultural industries are recognized as not only the holders of cultural diversity in Europe, but also as some of the most dynamic sectors of the EU's economy.

In the architectural realm, we need to articulate the organizational and spatial needs of these groups which are not homogeneous. It is more by defined "culture" than "functional" needs. New forms of work and entrepreneurial collaborations are emerging, such as: co-working, start-ups, hubs, cre- 
ative labs, fablabs, makerspaces, etc. These activities are at the intersection of educational and business functions as well as creative and technological domains. The new conceptual framework and the new activities require an appropriate environment. In our research of these phenomena, we considered the internal logic and motivation, the technological requirements, the organizational and socializing aspects, the design and image expectations, but also the connection to the surrounding community and the role in urban regeneration.

Brownfield sites are a consequence of our post-industrial transition. Large abandoned industrial areas, often in the wider city centre, need redefinition, redevelopment and community building. The new types of spaces and programs involving the creative and innovative community have an important role in revitalization by bringing these empty areas into focus at the start of their urban regeneration. In this paper, we will present some of the topics and projects covered by our research, such as creative incubators, where engineering competences meet artistically driven impulses; student housing, where innovation and new lifestyles merge; and community-driven hubs, where education, social responsibility and entrepreneurial activities meet. These architectural programs were important in establishing a new University of Zagreb's campus and the new centre for the local community of Sesvete in Zagreb, which are both brownfields.

\section{CASE STUDY 1: BORONGAJ CAMPUS IN ZAGREB}

The new University of Zagreb's campus was a former army base which had stared as the first airfield in Zagreb a hundred years ago. In order for the new Borongaj Campus to be successful, it had to be inspirational to the academic community, it also had to be conceptually progressive and it had to facilitate change. The campus was expected to promote innovation, bio-consciousness, creativity, interdisciplinary approach, knowledge transfer and provide a new educational experience. It had to be urban, inclusive, outreaching and cost-effective. The campus planning and design processes, initiated in 2008 , needed to address, among other things, the new reality of climate change, sustainable campus design, living laboratory practice, the need for social innovation, urban quality indicators, smart specialization strategy, as well as low university integration, the shift in educational paradigm and social networks. All of them challenged the design process with a myriad of questions on how to program, design and direct future processes.

Considering the 20-year development horizon of the campus, it was important to achieve some early goals that would signal the change of mindset at the University and a vision for the future. One such program is The Creative Incubator or The Centre for Creative Research, a place for collaboration of different disciplines as well as of exploration of the intersection of new technologies, artistic sensibility and social understanding. It was to be housed in an adapted army food storage building. At the new campus, the Cl's activities should inspire curiosity and they should make the campus a place of wider interest. The other important element for the new campus was student housing for some four thousand students. As a part of a green campus, it should be a living laboratory for sustainable development that introduces students to green technologies and sustainable lifestyles. Both needed an architectural program that had to be researched.

\section{The Creative Incubator - a space for interdisciplinary research and collaboration}

The Creative Incubator at the Borongaj Campus was planned as The Centre for Creative Research (Centre). The initial program for the Centre was defined by the representatives of selected academies and faculties. It was not easy to form the design brief since it had to address both artists' and engineers' needs as well as engage the wider public. The project for the conversion of the existing building into the Centre was conceived by an architect, Helena Paver Njirić (Careva, Baletić, Pap, 2015). This was the starting point for our research. In the research process, we looked at the facilities for interdisciplinary activities and identified the different programs and spatial configurations for new and innovative methods (Obrist, 2003). Based on these practices, we developed guidelines for an architectural model which we then used to analyse the proposed project. The established 
architectural proposal is primarily of functional-social character and it allows for multiple levels of collaboration by the disposition of the required spaces (Careva, 2012).

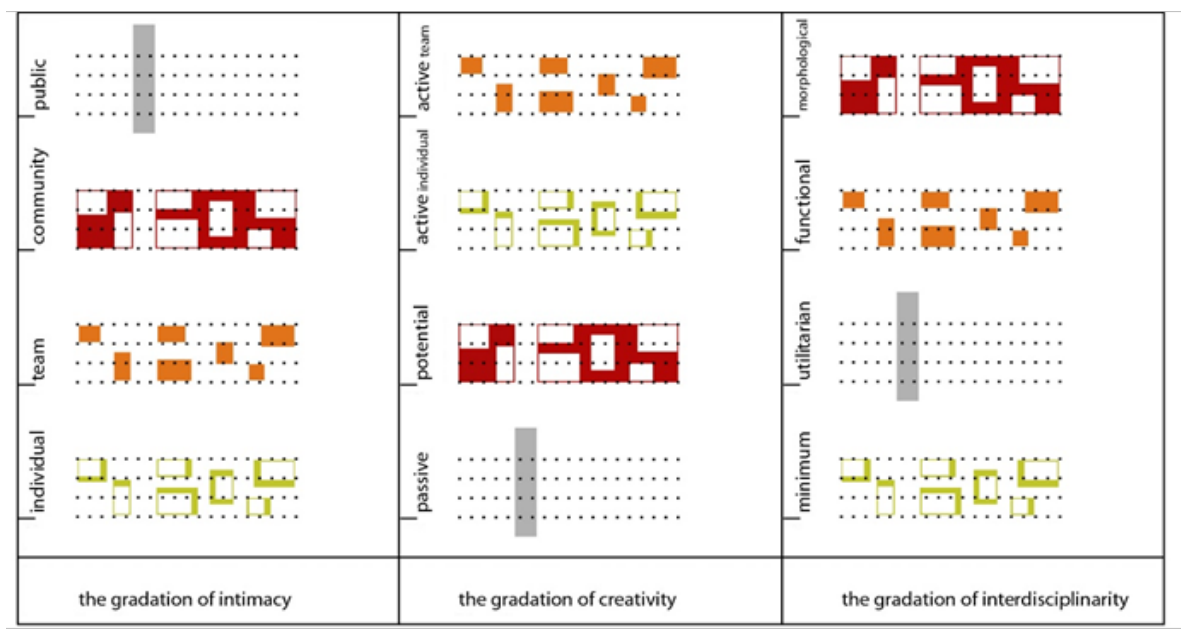

- Figure 1 The schematic representation of process and collaboration gradation by spatial units in The Creative Incubator. Source: Careva, K. (2012).

Since the creation of spaces for cooperation has been recognized as an imperative in the architectural model, it is also necessary to consider the possibilities of achieving the physical and/or visual connection of different spatial elements. We can follow connections both in linear and cross-spatial sequence. In linear sequence connecting intimate workspaces with labs leads to team building, connecting labs with common spaces leads to community creation, and connecting common spaces with the environment leads to a wider impact. Since creative principles often do not follow linear principles, the possibilities of spatial interconnections are highly encouraged but there needs to be a clearly defined connectivity control. The connection between intimate workspaces and shared spaces is controlled by the individual, the connection between the laboratory and the environment is controlled by the team, and the connection between laboratories and public spaces is controlled by the community. A fully controlled approach should be provided between the common areas and the public spaces of the Centre. Public space should be on the ground floor because the immediate vicinity of the traffic artery and the university lawn provide an urban context for opening the contents of the Centre to the community as well as using the university lawn as a spatial extension of the Centre (Careva, 2012).

\section{Student housing as a living lab for sustainability}

A sustainable campus offers an understanding of what our built environment should aspire to. It also stimulates the occupants, present and future professionals, to adopt the lifestyles that are crucial for the sustainable development of the planet (Friedman, 2016). In this context, all student housing on the campus should have the role of promoting sustainable living and social initiatives (Baletić, Lisac, Pap, 2020). Our aim was to designate one student pavilion for an innovative green building model that could be an educational, research and social tool for exploring advanced energy, technology and living proposition. The design of the building should be informed by the past housing tradition but should also advance the sustainable character of the campus through energy performance (nZEB, energy production and storage) and sustainable lifestyle choices. It should be accommodating to social innovation initiatives and be a showcase for new efficient construction methods and materials. Also, our interest was in the growing presence of the new IT technologies (IoT, Big Data, smart assistants, digital fabrication) and their implementation within student housing, 
having in mind the future notion of a Thinking building (Pap, 2019).
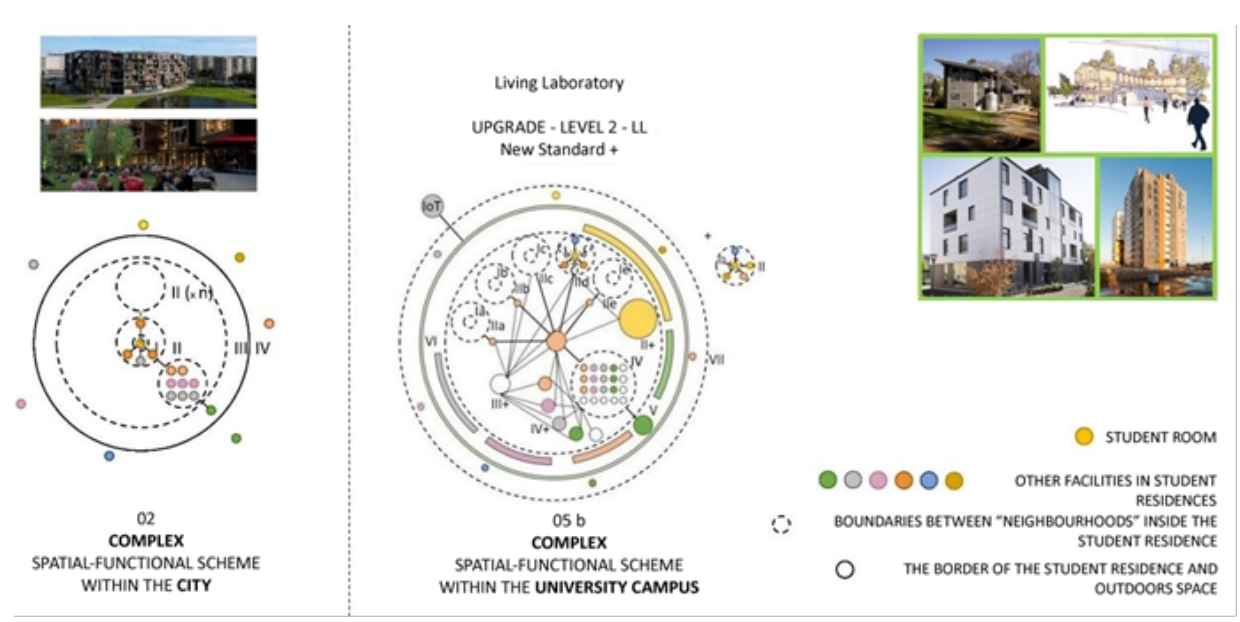

_ Figure 2 Schematic representation of the student experience offered by proposed new student housing programs. Left existing practice (one of the models), right advanced model (one of the two models). Source: Pap, M. (2019)

The change in the programming of student housing is determined by the interests of the future students, as well as by the expectations from the future workplace which demands new sets of skills. We propose that the housing program should be extended from only dormitory (present practice) to include spaces that promote co-working, skills development (makerspace, entrepreneurial training, creative expression) and social initiatives (urban gardening, second-hand items exchange, alternative food choices, volunteer activities). In this respect, the new university campus becomes a research and testing ground for future scenarios which will, with the involvement of business and public sector partners, turn it into a living laboratory for the new and emerging sustainable society (Pap, 2019).

\section{CASE STUDY 2: SESVETE QUARTER IN ZAGREB}

Sesvete is a city quarter on the east administrative edge of Zagreb. As it has grown from a village into a city quarter during the past decades, it has never developed a clear urban form or identity. The quarter has the highest population growth due to migration and natural growth. On average, it is the youngest community in Zagreb. As a community it is rather traditional, close-knit and has an entrepreneurial mindset.

Recently it has developed, through the local NGO activity and with the help of experts from the Faculty of Architecture, an urban self-consciousness that demands public spaces, parks and green spaces, bike lanes, additional public facilities, a better road network, a secure crossing of the railway, a new music school, a hub for small spin-off companies and makers culture, the relocation of the industrial zone, etc. and a new urban identity (Jošić, Baletić, 2016).

The ideal trigger for this new Sesvete downtown development has been a $125.000 \mathrm{~m} 2$ plot of a former meat factory Sljeme, now owned by the City of Zagreb. Its location is adjacent to the present centre of Sesvete, connected to the railway, and it will be well served by the future road network. Among many buildings on the plot, several stand out as appropriate for reuse and reconstruction. One of them, the vacant head office of the meat factory, presented a challenge for the development of a program for a community-driven hub that would energize the transformation of the brownfield 
into a new centre of the neighbourhood.

\section{Hub_Sesvete (HUB_S)}

Contemporary entrepreneurship trends include creating spaces where innovation is encouraged, experiences are shared, new values are created, and one's own business is started (Tvede, 2015). Through service sharing, spaces that house these new trends help people develop ideas more easily and cheaply, take advantage of business opportunities, and organize businesses (Diez, 2018). There are different forms of entrepreneurial incubators known worldwide. Hubs are one of them and they represent a new place where young people and businesses whose interests are focused on digital technologies come together and work. In addition to the already known spatial environment that offers support for successful business start-up, HUB_S would house, under the same roof, creative and innovative culture by aiming at creating new values. HUB_S should also stimulate cultural and creative industries.

The above-mentioned processes also have their theoretical background. They are based on the logic of the idea development, which is referred to as "design thinking" process. The process descriptions in literature vary, but we provide a description we have tested through practice (Pap, Vdović, Baletić, 2019). The design thinking process consists of three basic stages, and each one of them contains three steps. These are: to understand the problem (to understand - to perceive - to look at), then to explore the solutions (to imagine - to make - to check) and finally to materialize the vision (to tell - to start - to do business). Within such a process, one can perceive the activities of the hub. Since there is no direct role model for such a complex program within a single building, we have been checking our research findings through numerous discussions with persons running similar programs in other EU countries. Those discussions corroborated the assumptions that the established model could be successful, especially since it relates to the local community. The HUB_S project has been part of two present Horizon 2020 projects. The first, proGlreg, is dealing with Nature Based Solution principles in urban regeneration of brownfield sites into living green neighbourhoods. The HUB_S as a building will promote high level of energy efficiency as well as green roofs and walls. This green infrastructure approach will be promoted in the programs that the institution supports. The other project, Centrinno, will promote brownfield neighbourhood development through support of skills old and new, new digital technologies for production, as well as circular economy.

Within HUB_S, following entities would co-exist: a makerspace; a fablab; a co-working space, a space for start-ups; workshops and an event venue. We will briefly describe each of them. Makerspace is an easily accessible and well-equipped public physical space where people come together to share resources and knowledge, work on projects, connect and produce. Fablab offers (personal) digital production in a small workshop equipped with (most often) a range of flexible computer-controlled tools that cover different product sizes as well as different materials, with the goal to produce "just about anything". Co-working is a style of working in a collaborative work environment where people who are not normally employed by the same organization work together. Start-up is a level at which a previously formed idea, quite often checked through a prototype, is developed into a business venture. Workshop is an activity format that involves a larger number of people, focused on discussing specific problems and presenting experiences and possible solutions. Event venue allows organization of exhibitions, lectures, gatherings that can bring together people from HUB_S and from the community. Off-line space on the roof admits the users to the natural surrounding and allows them to enjoy the vegetation and fruit from the trees (Baletić, Jošić, Vdović, 2017).

The interested parties in this hub may be kindergartens, primary and secondary schools, colleges, but also associations, artisans, retired people, the unemployed etc. The Fablab involves modern digital technologies that can be interesting for students, engineers, consultants, craftsmen, entrepreneurs and the unemployed. The start-up phase represents the realization of business opportunities interesting for entrepreneurs, craftsmen, the unemployed, etc. HUB_S needs to stimulate and assist these processes in order to enhance the economic potential of the neighbourhood in which it oper- 
ates. It supports the creative and entrepreneurial ecosystem, in which several external factors need to be involved, such as: business angels, on-line crowdfunding, venture capital, etc. HUB_S could have great importance for the local community of Sesvete.

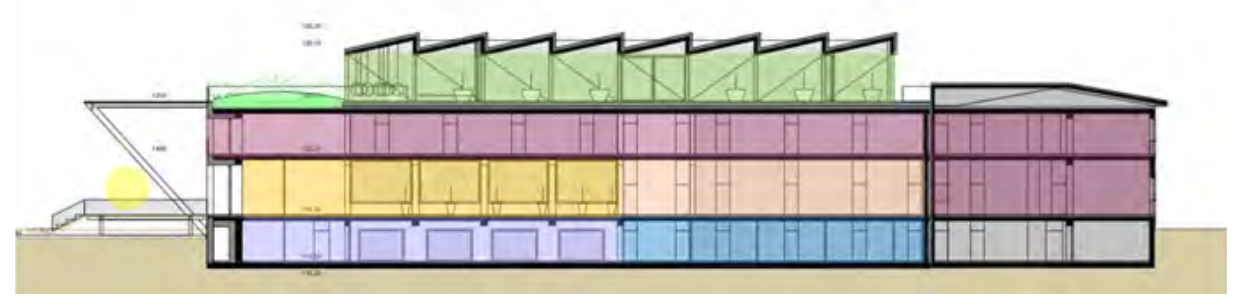

_ Figure 3: Schematic representation of HUB_S cross section situating different activities and collaboration. Source: Baletić, B., Jošić, M. (2020).

\section{TOOLS FOR URBAN REGENERATION}

HUB_S also plays an important role in the urban regeneration of the site. Sesvete has many young people who will increasingly seek a career in the application of modern technologies. The entrepreneurial spirit that is recognizable in this neighbourhood needs to be further developed and taken as an advantage and an opportunity to engage numerous small businesses which are affiliated with new technologies. These entrepreneurs should be able to find the necessary infrastructure in HUB_S to overcome challenges, or better said, open business opportunities, both in their local community and in the city. Therefore, the interconnection between the HUB_S and the local community is extremely important. The local community should participate in the HUB_S programs, and the HUB_S activities have to contribute to the development of that community. HUB_S should be inspired by the community and be community driven. Urban resilience to negative changes (climate, demographic, economic, social) is a significant issue these days and a lot of money is being invested in raising the capacity of cities and communities in that direction. In this respect, HUB_S has a dual role: it retains young people in the community and explores the solutions to the above-mentioned challenges the community faces. The expected positive effects are: stimulating the development of the local economy and entrepreneurship, the transition to new knowledge and skills, promoting the study of STE(A)M. Sesvete brownfield site is also the case study for our present research into the topics of green infrastructure and NBS (Nature Based Solutions) in proGlreg as well as FabCity strategies dealing with local and digital fabrication and circular economy in Centrinno.

Similar to HUB_S, the Creative Incubator and the Living Lab student housing at the Borongaj Campus are important building blocks of the campus in the process of promoting a new vision and the notion of change. The open and inviting nature of these facilities is an advantage that urban planning can build on. These new programs in reused buildings are a signal that the empty brownfield areas begin their transformation for the good of the community, be it local or academic. In creating the new campus, the university was determined to develop its research, education, development and management capacity that can be used in the transformation of the society. Therefore, understanding the future process is so important for the design of the campus. The new campus must stage "the four Is" - innovation, interdisciplinary collaboration, interaction and involvement (Baletić, Jošić, 2017). The living lab approach takes the R\&D and educational potential of the University and brings the interests of research, enterprise, government and social groups to the table to ensure the involvement and prosperity of the wider community. 


\section{CONCLUSIONS}

Every city has "underused pockets" and these pockets weaken the city's image, liveability, and productivity. For that reason, our discussion and the above explained topic of the paper is set in the context of brownfield reuse with the aim of establishing a new urban identity and quality of place. Our intentions strived towards understanding and shaping appropriate architectural recommendations for the emerging forms of work and collaboration. The logic of these spaces is reflected in the possibility of sharing ideas and building the awareness of community aspirations. Particularly interesting in this regard are spaces whose purpose is not clearly defined, i.e. spaces that can be used in various (unpredictable) ways. Not only do these spaces serve the individual in different ways, they also serve informal socializing that has proven to be one of the best ways to gain new interdisciplinary ideas. By giving people different environments for work and socializing, we encourage their creativity, which should be the most valuable tool for future success of both individuals and society.

\section{REFERENCES}

- Baletić, Bojan; Jošić, Mladen. 2017. "An urban plan for a smart and resiliant community - A case study of the new university campus Borongaj". In Zagreb, MED.NET3 Resili(G)ence, ADD scientific meeting, conference proceedings, curated by Gausa, Manuel; Andriani, Carmen; Gagnoni, Raffaella. ISBN 978-84941264-6-8. Barcelona: Paperdoc.

- Baletić, Bojan; Jošić, Mladen; Vdović, Roberto. 2017. HUB_S (program and redesign of the head office of former Sljeme meat industry in Sesvete for HUB_S), Expert study. Zagreb: Faculty of Architecture, University of Zagreb, commissioned by City of Zagreb.

- Baletić, Bojan, Lisac, Rene, Pap, Morana. 2020. "A transition to sustainable lifestyles: The role of universities." In Higher education and sustainability opportunities and challenges for achieving sustainable development goals, edited by Ulisses Manuel de Miranda Azeteiro and J.Paulo Davim, 197-222. Boca Raton London New York: CRC Press. Taylor \& Francis Group.

- Careva, Kristina. 2012. The architectural model of space for interdisciplinary research in art and technology, Doctoral dissertation. Zagreb: University of Zagreb, Faculty of Architecture.

- Careva, Kristina; Baletić, Bojan; Pap, Morana. 2015. "Transformation of the industrial architecture heritage in the space for interdisciplinary research - an encouragement for new spatial development strategies." In Proceedings of the international scientific conference "Spatial and developmental opportunities of cultural heritage", edited by Obad Šćitaroci, Mladen, 514-519. Zagreb: University of Zagreb, Faculty of Architecture.

- Diez, Tomas. 2018. Fab City: the mass distribution of (almost) everything. Institute for advanced architecture of Catalonia, Barcelona.

- Friedman, Avi. 2016. Innovative Student Residences: New Directions in Sustainable Design. Mulgrave, Victoria: The Images Publishing Group.

- H2020_Call: SCC-02-2016-2017: Demonstrating innovative nature-based solutions in cities, proGIreg

- Productive green infrastructure for post-industrial urban regeneration. Project lifetime: 2018-2023.

- H2020_Call: CE-SC5-20-2019: Transforming historic urban areas and/or cultural landscapes into hubs of entrepreneurship and social and cultural integration, CENTRINNO - New CENTRalities in INdustrial areas as engines for inNOvation and urban transformation. Project to start in 2020.

- Jošić, Mladen; Baletić, Bojan. 2016. Starting points for Green and Blue Sesvete project, Expert study. Zagreb: Faculty of Architecture, University of Zagreb, commissioned by City of Zagreb.

- Obrist, Hans Ulrich. 2003. Interviews, Volume I, Milano: Edizioni Charta.

- Pap, Morana. 2019. Spatial and functional model of student residences in the context of university campus, Doctoral dissertation. Zagreb: University of Zagreb, Faculty of Architecture.

- Pap, Morana, Vdović, Roberto, Baletić, Bojan. 2019. "Design thinking method in scientific research, education and business practice". In Prostor Vol. 27, No. 2 (58): 334-347.

- Tvede, Lars. 2015. The creative society: how the future can be won. LID Publishing Ltd, London. 